\title{
Correction to: Adipose mesenchymal stem cell exosomes promote wound healing through accelerated keratinocyte migration and proliferation by activating the AKT/HIF-1 $a$ axis
}

\author{
Published online: 2 July 2020 \\ C) Springer Nature B.V. 2020 \\ Correction to: Journal of Molecular Histology \\ https://doi.org/10.1007/s10735-020-09887-4 \\ In the original publication of the article, the name of one of \\ the corresponding authors was published incorrectly. The \\ name should be 'Ke Tao' instead of 'Kao Tao'. The cor- \\ rected author group is given in this Correction.
}

Yue Zhang ${ }^{1} \cdot$ Fei Han ${ }^{1} \cdot$ Lan Gu ${ }^{1} \cdot$ Peng $\mathrm{Ji}^{1} \cdot$ Xuekang Yang ${ }^{1} \cdot$ Mengdong $\mathrm{Liu}^{1} \cdot \mathrm{Ke} \mathrm{Tao}^{1} \cdot$ Dahai Hu$^{1}$

Publisher's Note Springer Nature remains neutral with regard to jurisdictional claims in published maps and institutional affiliations.

The original article can be found online at https://doi.org/10.1007/ s10735-020-09887-4.

Ke Tao

taoke918@fmmu.edu.cn

$\bowtie$ Dahai $\mathrm{Hu}$

xjburnlab@163.com

1 Department of Burns and Cutaneous Surgery, Xijing

Hospital, The Fourth Military Medical University, 127

Changle West Road, Xi'an, Shaanxi 710032, China 